\title{
Active Compliant PID Learning Control for Grinding Robots
}

\author{
Lubna Farhi ${ }^{1}$, Farhan Ur Rehman ${ }^{2}$ \\ RECEIVED ON 11.04.2020, ACCEPTED ON 20.12.2020
}

\begin{abstract}
This article proposes a Proportional, Integral, and Derivative (PID) learning controller for rigid robotic disk grinding mechanism. It has been observed that the stiffness of the robotic arm for a grinder has a direct correlation with the sensitivity of the grinding forces. It is also drastically influenced by the end-effector path tracking error resulting in limited accuracy of the robot. The error in robot's accuracy is also increased by external interferences, such as surface imperfections and voids in the subject material. These errors can be mitigated via efficient feedback. In the proposed methodology, the controller gain is tuned by implementing a learning-based methodology to PID controllers. The learning control for the robotic grinding system helps by progressively decreasing error between the actual grinded paths and required trace. Experimental results demonstrate that as the grinder machines the required path iteratively, its grinding accuracy improves due to the learning algorithm.
\end{abstract}

Keywords: Grinding Robot, PID, Learning Controller, Interferences

\section{INTRODUCTION}

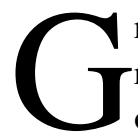
rinding is a mechanical process intended to remove a very thin and even layer of material on the outer edge of the workpiece. Field practice had demonstrated difficulties in grinding complex shaped workpieces like a marine propeller or a turbine blade. The desired surface morphology of these workpieces demands that the end-effector of the manipulator keeps a stable contact force with the environment, while the grinding tool moves along the profile of the workpiece. To perform such a task, concurrently, both force and position of the robot should be controlled [1].

However, it must be noted that controlling the repeated tracking behavior on a desired trajectory is generally an extremely difficult task. This difficulty can be attributed to the empirical dynamic interferences, perturbative torques and naturally inherent nonlinearities in the robot. These error inducing factors create a nonlinear coupled system where they cannot be predicted and measured beforehand. Despite these uncertainties, grinding robots are approximated to linear systems in controller design. This leads to periodic errors during repetitive machining motions, caused by inherent structural and dynamic interferences. It is because of this uncertainty, improving machining accuracy of repetitive tasks via learning through trial is highly desirable.

In the proposed system, tracking and positioning control are included to achieve the stable responses of robotic grinding system. Because of the additive nonlinearities, dynamic interferences, and disturbances torque in practically nonlinear coupled systems, the unpredictable dynamic interferences occurs between mechanical structure and grinding bit [2]. The proposed control system be modeled to address this issue as a linear system and its repetitive

${ }^{1}$ Department of Electronic Engineering, Sir Syed University of Engineering and Technology, Karachi, Pakistan. Email: lubnafarhi@yahoo.com (Corresponding Author)

${ }^{2}$ Department of Mechanical Engineering, University of Toronto, Canada. Email: farhanrehman@mail.utoronto.ca This is an open access article published by Mehran University of Engineering and Technology, Jamshoro under CC BY 4.0 International License. 
behavior as it is useful to achieve optimized tracking and accuracy at the same time by learning iterative trials.

Nowadays, many researchers are working on the learning control methods to get precise results and, the designed controllers are consistently reducing the errors [3-5]. When it comes to practical implementation, few learning control methods need very detailed information of the system characteristics that become complicated in comparison to traditional PID controllers. However, still in conventional PID controller, tuning the gains of controller is a difficult task, As the researchers mentioned that conventional PID controller is cost effective and less complicated, but they used upgraded microprocessors which includes digital signal processing techniques (DSP's) that makes more costly and computationally heavy [6, 7].

Moreover, PID controller is a very feasible option to implement in various applications, but somehow it is not suitable in applications that require high machining accuracy, compensation in nonlinearity, adaptation in parameter variations. In order to fulfil these missing features, our suggested methodology involved a PID controller where proportional, integral and derivative controllers are arranged in a unique way in comparison to conventional PID controllers. A PID type learning controller in discrete time domain is proposed in this paper which can be easily implemented. After achieving a minimum suitable conditions, the output error is minimized just after having number of trials without being affected by the change in parameters $[8,9]$.

\section{METHODOLOGY}

Grinding machine tool dynamic equations having $\mathrm{N}$ degree of freedom can be written as:

$$
\mathrm{I}(\mathrm{r}(\mathrm{t})) \ddot{\mathrm{r}}(\mathrm{t})+\mathrm{F}(\mathrm{r}(\mathrm{t}), \dot{\mathrm{r}}(\mathrm{t}))+\mathrm{G}(\mathrm{r}(\mathrm{t}))+\mathrm{Td}(\mathrm{t})=\mathrm{T}
$$

In above equation, $r(t), \dot{r}(t), \ddot{r}(t) \in R^{K}$ are positional variables that respectively represent the location, velocity and acceleration of each joint individually. $\mathrm{I}((\mathrm{t})), \mathrm{F}(\mathrm{r}(\mathrm{t}), \dot{\mathrm{r}}(\mathrm{t}))$ and $\mathrm{G}(\mathrm{r}(\mathrm{t}))$ are the matrix of inertia, centrifugal force caused by angular momentum and loading force vectors, accordingly. $\mathrm{Td}(\mathrm{t}) \in \mathrm{R}^{\mathrm{K}}$ represents the disturbed torque vector because of unmodeled dynamics or unpredictable external interferences while $\mathrm{T}(\mathrm{t}) \in \mathrm{R}^{\mathrm{K}}$ represents the input torque vector applied to joints [10].

Equation (1) demonstrates the behavior of nonlinear coupled systems. The nonlinear characteristic in equation (1) adds complexity in analyzing the entire system along with the controller. Specifically, when the system is analyzed under discrete time domain on the nonlinear coupled system the mathematical analysis becomes more complicated (1). Because of the complication of mathematical analysis of nonlinear systems, linearized models are preferred for the grinding robot for a defined trajectory in various applications of controller design.

Therefore, linear time-varying approach which illustrates the linearized behavior of the model for robot tool for a defined path to be followed or machined just to analyze the nonlinear behavior of coupled system in (1) having an adaptive control approach, that is applied on the microprocessor. In this paper, utilizing the principle of linearized models to improve controller accuracy and efficacy will be discussed.

Consider a linear periodic time-varying system that defines a linear model around a defined path to be traced or machined.

$r(i+1)=A(i) r(i)+B(i) u(i)+D(i) w(i), r(0)=r_{0}$ $y(i)=C(i) r(i)$

where $\mathrm{i}$ is the sampling index number. The variable $\mathrm{r}(\mathrm{i})$ is the $\mathrm{n} \times 1$ state vector, $\mathrm{u}(\mathrm{i})$ is the $\mathrm{m} \times 1$ control input vector, $y(i)$ is the $\mathrm{p} \times 1$ output vector and lastly, w(i) is the $n \times 1$ unknown external disturbance vector. Equation (2) above also requires an assumption that $\mathrm{A}(\mathrm{i}), \mathrm{B}(\mathrm{i}), \mathrm{C}(\mathrm{i})$ and $\mathrm{D}(\mathrm{i})$ are $n \times n, \mathrm{n} \times \mathrm{m}, \mathrm{p} \times \mathrm{n}$ and $n \times n$ time-varying matrices with a period $\mathrm{N}$ such that

$$
\begin{aligned}
& A(i+N)=A(i), \\
& B(i+N)=B(i) \\
& C(i+N)=C(i), \\
& D(i+N)=D(i)
\end{aligned}
$$

The unknown external disturbance vector can be 
written as

$\mathrm{w}(\mathrm{i}+\mathrm{N})=\mathrm{w}(\mathrm{i})$

Next, let us assume that $\mathrm{S}$, the mapping from $\{\mathrm{u}(\mathrm{i}), \mathrm{i} \in$ $[0, \mathrm{n}-1]\}$ to $\{\mathrm{x}(\mathrm{i}), \mathrm{i} \in[0, \mathrm{~N}]\}$, and $\mathrm{R}$, the mapping $\left\{\mathrm{r}_{0}, \mathrm{u}(\mathrm{t}), \mathrm{i} \in[0, \mathrm{~N}-1\} \leftrightarrow\{\mathrm{y}(\mathrm{i}), \mathrm{i}[0, \mathrm{~N}]\}\right.$, are oneto-one mappings. This means that the unique input and state vectors exist for the given output vectors. Furthermore, we define the norm of the $n \times 1$ vector $\mathrm{f}=(\mathrm{f} 1, \mathrm{f} 2, \ldots, \mathrm{fn})^{\mathrm{T}}$ as $\|\mathrm{f}\|=\max _{1 \leq i \leq n}\left|\mathrm{f}_{\mathrm{i}}\right|$, the norm of the $n \times$ m matrix $\quad \mathrm{G}=\left\{\mathrm{g}_{\mathrm{ij}}\right\} \quad$ as $\|\mathrm{G}\|=\max _{1 \leq \mathrm{i} \leq \mathrm{n}} \sum_{\mathrm{i}=1}^{\mathrm{m}}\left|\mathrm{g}_{\mathrm{ij}}\right|$, and the function norm of the $x \times 1$ vector $\mathrm{h}(\mathrm{i})$ as $\|\mathrm{h}(\mathrm{i})\|_{\lambda}=\sup _{\mathrm{i} \in[0, \mathrm{~N}-1]} \lambda^{\mathrm{i}}\|\mathrm{h}(\mathrm{i})\|$, $0<\lambda<1$.

Now, we define the control input which defines the path having minimum threshold of perfection that can be expressed as follows.

Let the desired output path that is needed to be tracked or machined be denoted by $\mathrm{y}_{\mathrm{d}}(\mathrm{i}), \mathrm{i} \in[0, \mathrm{~N}]$ and the tolerance bound for that path be described by $\varepsilon$. Then the control input vector $\mathrm{u}(\mathrm{i}), \mathrm{i} \in[0, \mathrm{~N}]$ needs to be such that $y_{k}(i)$, the actual tracked path of the linear time-varying system in (2), satisfies

$\left\|y_{d}(i)-y_{k}(i)\right\| \leq \varepsilon, \quad i \in[0, N]$

where $\varepsilon>0$.

As discussed above, this issue is usually resolved by applying a conventional PID controller in grinding control system in numerous applications of an industry. In order to achieve the precise results as mentioned in the input program, the motion controller must have optimized values of gain for the PID control. Due to unpredictable disturbance torque and other dynamics that are not modeled make it complicated to sustain the PID control gains at optimal values throughout. It might become a serious issue in maintaining the quality of industrial requirements. To resolve this issue a learning function might be implemented into the ordinary PID controller, thus significantly enhancing the controlling performance. $K_{P}, K_{I}$ and $K_{D}$ are control gain matrices of PID controller.

$$
\begin{aligned}
& u_{k+1}(i)=u_{k}(i)+K_{P} e_{k}(i+1)+K_{I} \sum_{n=1}^{i+1} e_{k}(n) \\
& +K_{D}\left[e_{k}(i+1)-e_{k}(i)\right], \quad i \in[0, N-1]
\end{aligned}
$$

is given by

$e_{k}(i)=y_{d}(i)-y_{k}(i), \quad i \in[0, N-1]$

In applying of (6), in the initial trial, it is observed that control input is similar as it was in the conventional PID controller. In the second trial of actual system, responses were not according to the system output values, hence error was integrated with the second input of the system. This is the change analyzed between output value $y_{d}(i)$ and actual system output in the initial trial, in this way (6). Control input is generated in this manner just after the second trial (8). So, the suggested learning control system can be expressed by

$$
\begin{aligned}
& \left.\mathrm{r}_{\mathrm{k}}(\mathrm{i}+1)=\mathrm{A}\right)(\mathrm{i}) \mathrm{r}_{\mathrm{k}}(\mathrm{i})+\mathrm{B}(\mathrm{i})_{\mu \mathrm{k}}(\mathrm{i})+\mathrm{D}(\mathrm{i}) \mathrm{w}_{\mathrm{k}}(\mathrm{i}) \\
& \mathrm{r}_{\mathrm{k}}(0)=\mathrm{r}_{0} \\
& \mathrm{y}_{\mathrm{k}}(\mathrm{i})=\mathrm{C}(\mathrm{i}) \mathrm{r}_{\mathrm{k}}(\mathrm{i}) \\
& \mu_{\mathrm{k}}(\mathrm{i})=\mu_{\mathrm{k}-1}(\mathrm{i})+\mathrm{K}_{\mathrm{p}} \mathrm{e}_{\mathrm{k}-1}(\mathrm{i}+1)+ \\
& \mathrm{K}_{\mathrm{I}} \sum_{\mathrm{n}=1}^{\mathrm{i}+1} \mathrm{e}_{\mathrm{k}-1}(\mathrm{n})+\mathrm{K}_{\mathrm{D}}\left[\mathrm{e}_{\mathrm{k}-1}(\mathrm{i}+1)-\mathrm{e}_{\mathrm{k}-1}(\mathrm{i})\right] \\
& \mathrm{e}_{\mathrm{k}-1}(\mathrm{i})=\mathrm{y}_{\mathrm{d}}(\mathrm{i})-\mathrm{y}_{\mathrm{k}-1}(\mathrm{i})
\end{aligned}
$$

This can be clearly seen in Fig. 1. Having learning operation based on the previous states, it is expected to achieve the enhanced control results due to the learning based control technique. Mathematical analysis is derived for the proof in the later section.

\section{EXPERIMENTAL RESULTS}

PID-type iterative learning controller has been tested performing different experiments. Experimental results of grinding of different shapes are shown in Fig. 3-5. It can be noted that the error between the desired and actual machined path has reduced, indicating a higher machining accuracy. This accuracy can be further improved upon by fine tuning the PID controller gains.

Different parameters can also be evaluated to determine the effectiveness of the proposed control strategy. Some of these include measuring the variable 


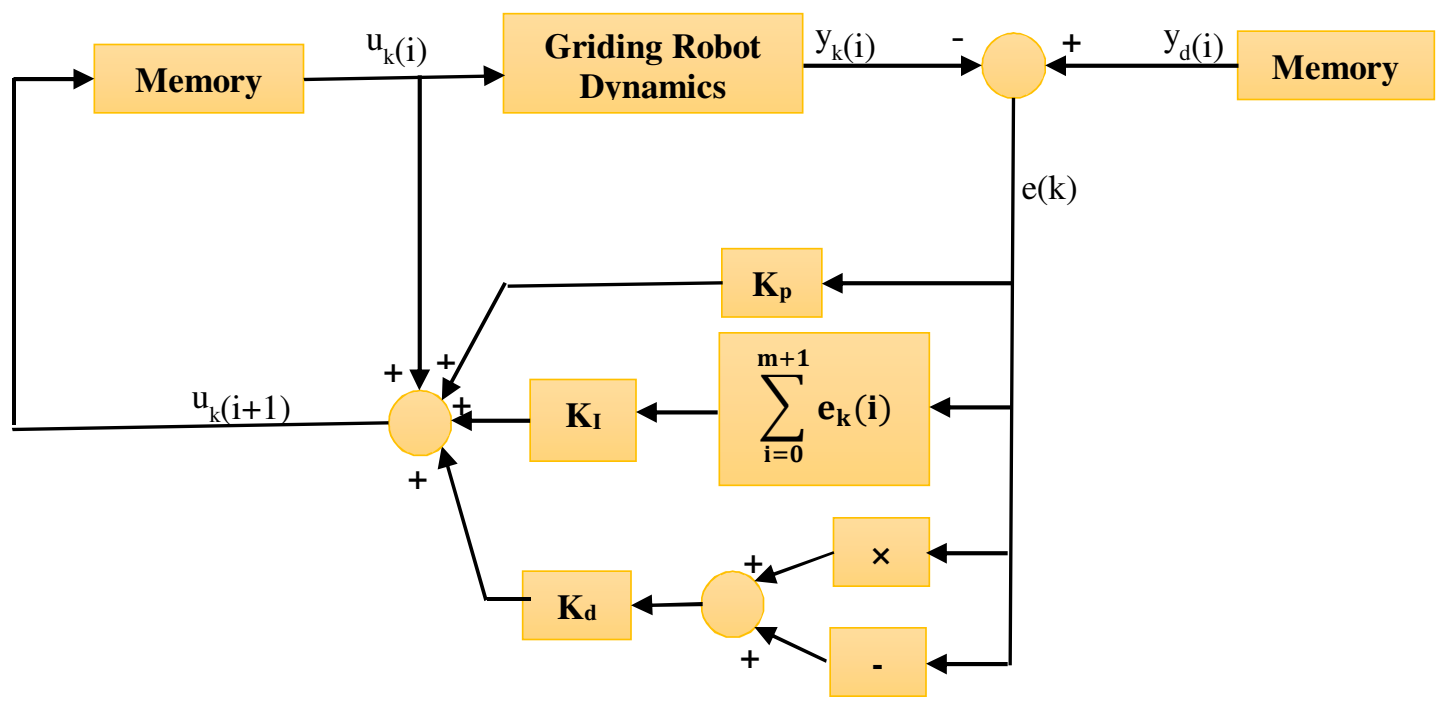

Fig. 1: Block Diagram: PID Learning Controller

load torque, variable speed, and other independent parameter variations. These factors can also be used to judge the flexibility of the control system.

Experimentation also showed that electrical parameters were also influenced by physical changes in the system. As the operating temperature changed, the actuator currents experienced by the controller were also affected. Nonetheless, these problems can be dealt with by utilizing an online tuning rule that the controller can be connected to. This function would introduce adaptability into the design, allowing it to optimize the controller output depending on external factors such as temperature $[11,12]$.

The step response of LPID controller tuning of Fig. 2 shows that the system will reach the stability quickly than the system under the conventional PID controller and the peak overshoot is decrease, where the system takes short time to reach the steady state and that the system got good response.

The analysis of the expected results in order to authenticate the level of accuracy of proposed system during operation is presented below.

To check the effect of an angle having some speed in the object formation was conducted. A line having 5 $\mathrm{cm}$ length and depth of $2 \mathrm{~mm}$ of length was used to replicate a 2D shape. These designs are made and its time has been noted using stopwatch.

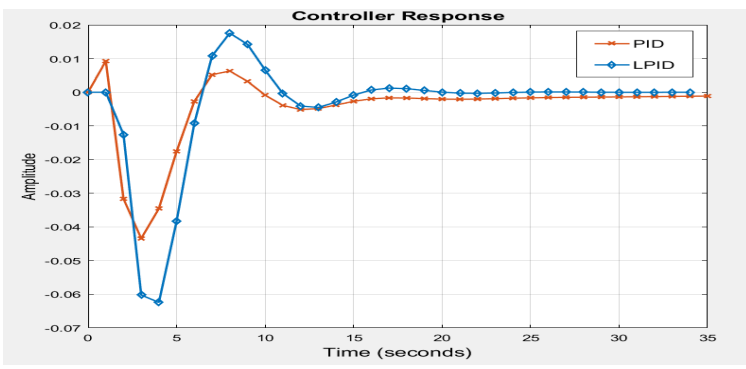

Fig. 2: Step response of system under conventional PID controller and Learning PID controller

Table 1 shows the relation between different shapes and the time needed to complete the task.

\begin{tabular}{|c|c|c|}
\hline \multicolumn{3}{|c|}{ Table 1: Speed Test } \\
\hline S.No & Shapes & $\begin{array}{c}\text { Computation } \\
\text { Time (s) }\end{array}$ \\
\hline 1 & Line & 5,6 \\
\hline 2 & Rectangle & 10,12 \\
\hline 3 & Triangle & 9,10 \\
\hline 4 & Circle & 9,2 \\
\hline
\end{tabular}

The results of griding robot for this paper and the previous research papers are compared and the results are shown below:

Table 2 shows the comparison of different techniques and their responses accordingly in terms of accuracy and complexity of the techniques applied. Fig. 3 compares the efficiency of the proposed controllers with that of the existing controllers. 


\begin{tabular}{|c|c|c|c|c|}
\hline \multicolumn{5}{|c|}{ Table 2: Comparison } \\
\hline Year & 2016 & 2015 & 2012 & 2019 \\
\hline References & {$[4]$} & [13] & [14] & Proposed \\
\hline Technique & $\begin{array}{l}\text { Multi- } \\
\text { sensor } \\
\text { data } \\
\text { Fusion }\end{array}$ & $\begin{array}{l}\text { PID } \\
\text { Using } \\
\text { PFGA }\end{array}$ & $\begin{array}{c}\text { Fuzzy } \\
\text { Control } \\
\text { with } \\
\text { PID }\end{array}$ & $\begin{array}{c}\text { PID } \\
\text { Learning } \\
\text { controller }\end{array}$ \\
\hline Accuracy & High & High & High & High \\
\hline Complexity & High & High & High & Low \\
\hline
\end{tabular}

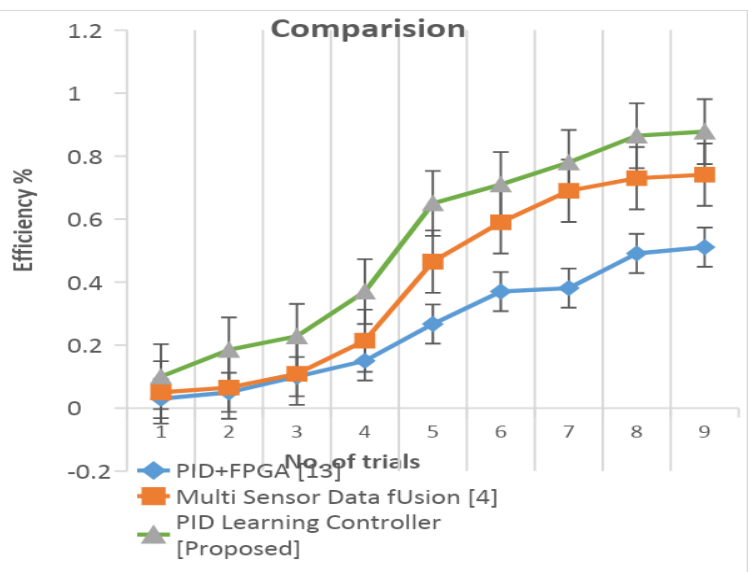

Fig. 3: Performance comparison of proposed PID

learning controller with prior techniques

Figs. 4, 5, and 6 show the results of the proposed learning model for the triangular, circular, and rectangular shapes. The polygons drawn with solid lines between the inner and outer dotted polygons represent the desired path whereas the dotted lines themselves show the actual path of the grinder. Results indicate that the grinding robot approaches the desired path in 2 degrees of freedom ( $\mathrm{x}$ and $\mathrm{y}$ axis) when it was grinding the three shapes. Consecutive grinding passes resulted in a reduction in error between the desired and actual paths of the grinder.

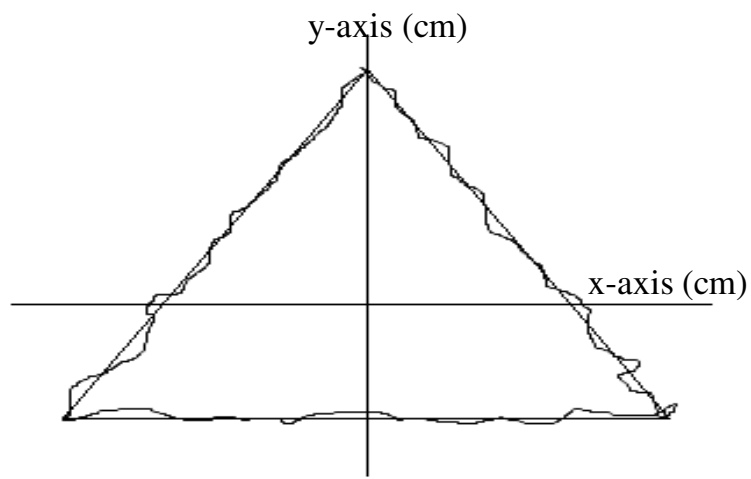

Fig. 4: Results achieved in a triangular shape

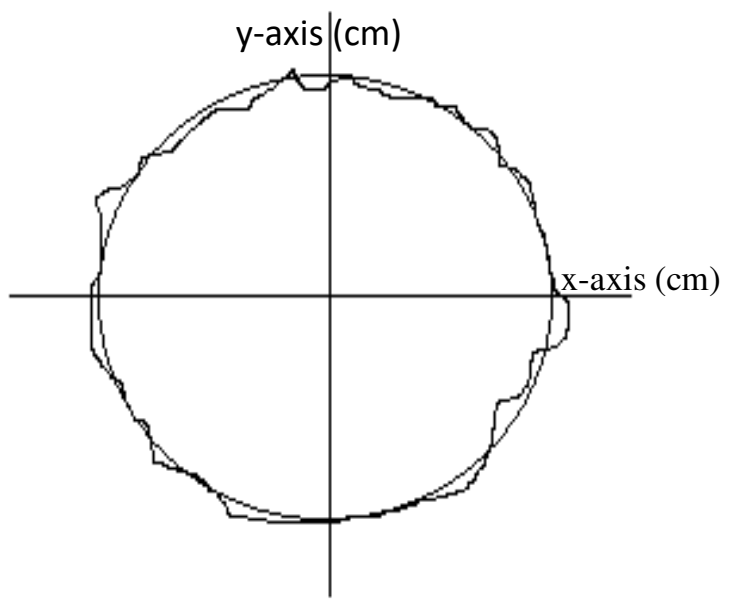

Fig. 5: Results achieved in a circular shape

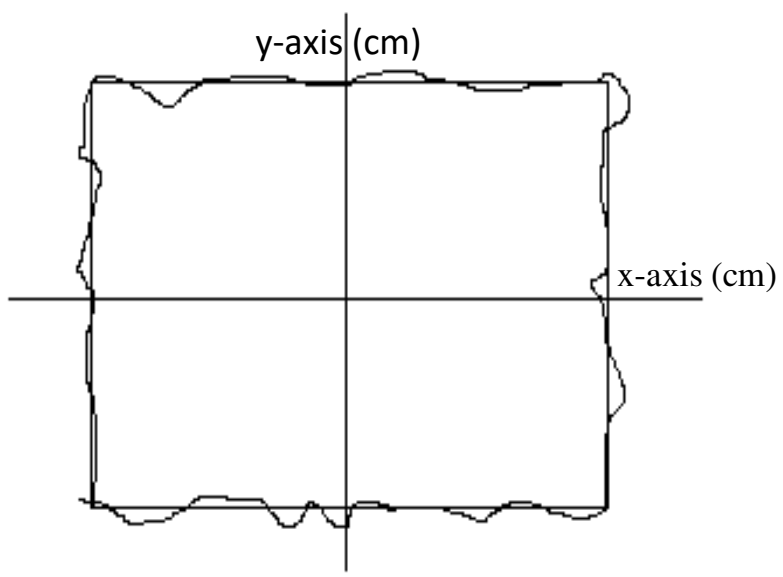

Fig. 6: Results achieved in a rectangular shape

\section{CONCLUSION}

The proposed active compliant PID learning controller for grinding Robot promises the convergence of the output even when the system parameters are ambiguous due to material disturbances that cannot be predicted. The performance of the proposed learning controller has been investigated through comparison of workpieces of different shapes i.e. circle, triangle and square. Their observation showed that the error between the paths and require traced gradually reduced as the drill, lathe or bit iteratively passed through the material. The comparison of results demonstrated that the accuracy can be greatly improved by the proposed learning controller in spite of inherent nonlinearity and dynamic interferences present in system. As a result, it is concluded that the

Mehran University Research Journal of Engineering and Technology, Vol. 40, No. 4, October 2021 [p-ISSN: 0254-7821, e-ISSN: 2413-7219] 
proposed learning controller is effective for grinding robot.

\section{REFERENCES}

1. Hofmann J., "Industrie 4.0”, CNC-Handbuch, pp. 725-738, München: Carl Hanser Verlag GmbH \& Co. KG, 2017.

2. Xu X. W., Newman S. T., "Making CNC machine tools more open, interoperable and intelligent - A review of the technologies. Computers in Industry”, Computers in Industry, Vol. 57, No.2, pp. 141- 152, 2006.

3. Xiao W., Zheng L., Huan J., Lei P., “A complete $\mathrm{CAD} / \mathrm{CAM} / \mathrm{CNC}$ solution for STEP-compliant manufacturing", Robotics and ComputerIntegrated Manufacturing, Vol. 31, No. C, pp. 110, 2015.

4. Duro J. A., Padget J. A., Bowen C. R., Kim H. A., Nassehi A., "Multi-sensor data fusion framework for CNC machining monitoring", Mechanical Systems and Signal Processing, Vol. 66-67, pp. 505-520, 2016.

5. Sencer B., Altintas Y., Croft E. "Feed optimization for five-axis CNC machine tools with drive constraints", International Journal of Machine Tools and Manufacture, Vol. 48, No. 78, pp. 733-745, 2008.

6. Shinskey F.G., "PID Control”, In: Webester J.G., Eren H. (Eds.), Measurement, Instrumentation, and Sensors Handbook - Spatial, Mechanical, Thermal, and Radiation Measurement, Second Edition, 2017.

7. Yeung C. H., Altintas Y., Erkorkmaz K., "Virtual CNC system. Part I. System architecture", International Journal of Machine Tools and Manufacture, 2006.
8. Saeed A., Ezzi D. M., Niazi A. R. K., Hans M. M., Amin W., "Steps towards sustainability: Energy generating swing ride", Proceedings of the 9th International Renewable Energy Congress (IREC), pp. 1-5, Hammamet, Tunisia, 20-22 March 2018.

9. Saeed A., Zubair M., Khan F. A., Mairaj F., Siddique M., Shiwlani A., "Energy Savings through Ammonia Based Absorption Chiller System: A proposed Strategy", Proceedings of the 7th International IEEE Conference on Renewable Energy Research and Applications (ICRERA), Paris, France, 2018.

10. Neugebauer R., Denkena, B., Wegener, K., "Mechatronic Systems for Machine Tools", CIRP Annals, Vol. 56, No.2, pp. 657-686, 2007.

11. Ramesh R., Mannan M. A., Poo A. N., "Tracking and contour error control in CNC servo systems", International Journal of Machine Tools and Manufacture, Vol. 45, No.3, pp. 301-324, 2005.

12. Yusof Y., Latif K., "New interpretation module for open architecture control based CNC systems", Procedia CIRP, Vol. 26, pp. 729-734, 2015.

13. Ponce P., Molina A., Tello G., Ibarra L., MacCleery B., Ramirez M., "Experimental study for FPGA PID position controller in CNC Micromachines", IFAC - Papers OnLine, Vol. 48, No.3, pp. 2203-2207, 2015.

14. Xie D., Zhu J. Q., Wang F., "Fuzzy PID control to feed servo system of CNC machine tool", Procedia Engineering, Vol. 29, pp. 2853-2858, 2012. 